\title{
Influence of static and cyclic climate condition on bending properties of wood plastic composites (WPC)
}

\author{
A. K. Bledzki, M. Letman-Sakiewicz, M. Murr* \\ Institut für Werkstofftechnik, Kunststoff- und Recyclingtechnik, Universität Kassel, Germany
}

Received 16 November 2009; accepted in revised form 16 April 2010

\begin{abstract}
Wood and natural fiber reinforced plastic composites are established for several fields like decking, transportation and automotive applications. In the last decade, extensive researches were conducted to improve the mechanical properties, such as incorporating additives like maleic anhydride grafted polypropylene (MAH-PP). The major challenge is to keep the properties in face of the environmental influence the parts are exposed to. Therefore it's necessary to find the hardest impact factor concerning the mechanical properties. Water absorption (static and cyclic) of the composites was examined at two different temperatures $\left(23,50^{\circ} \mathrm{C}\right)$. A correlation between duration, kind of conditioning, temperature and modification was established. The results indicate that the coupling agent MAH-PP improved significantly the water resistance of the wood plastic composites under climatic conditions and higher temperature accelerated the rate of water absorption of the composites. The decrease of mechanical properties related to cyclic conditions is partially reversible and therefore the cyclic exposition shows less effects compared to static conditions.
\end{abstract}

Keywords: biocomposites, WPC, coupling agent, water absorption, weathering

\section{Introduction}

Wood plastic composites (WPC) containing wood plastics and additives were used to substitute wood products as well as standard plastics [1-3].

Currently, more than 1.5 million tons of WPC per year are produced worldwide. With about 1 million tons, the USA represents the largest market by far, followed by China (200 000 tons), Europe (170 000 tons), and Japan (100 000 tons). In Europe, Germany is the leading producer of wood polymer materials and, furthermore, the most significant constructor of machines.

The most important application areas of WPC are the automobile industry (automobile interior) as well as decking's and floorings, especially those for outdoor use, which are increasingly establishing themselves as an alternative to tropical- or other kinds of high quality-wood and which are subject to a two-digit growth in sales volume annually.
Chinese WPC industry shows particular dynamics, where, a growth of 30 per cent can be recorded annually; until 2015, the WPC production in China is estimated to increase up to 5 million tons [4].

Due to their increased water absorption and thus, lower dimension stability, these composites are not suitable for all areas of application (e.g. wet areas). However, the desired stability can be achieved by chemical modification, for example by acetylation or by adding coupling agents [5].

To achieve the desired composite properties, the wood fibres (particles) were modified with a coupling agent. By using maleic anhydride grafted PP as a coupling agent, an increase in water resistance as well as a rise in mechanical data in comparison to untreated composites could be demonstrated [6-12].

The aim of this study was to clarify the influence of water exposition as well as static and cyclic cli- 
matic conditions to the composites. Static and cyclic conditions were applied at two different temperatures $\left(23,50^{\circ} \mathrm{C}\right)$ and a correlation between duration, kind of conditioning, temperature and modification was evaluated.

\section{Composition of natural fibres}

The hydrophilic characteristics of natural fibres result from their composition (Figure 1 and 2).

Natural fibers are composed of fibre bundles that consist of several elementary fibres. These elementary fibres are made up of individual layers in which cellulose fibrils are differently oriented. The middle lamella is no integral constituent of the fibre cell wall, but an exterior layer that protects the fibre from moisture expansion. In the primary wall, the cellulose fibrils form a network. The secondary wall consists of three layers. At $S_{1}$ and $S_{3}$, there is a thinner layer and in the $S_{2}$, a thicker one accounts for approx. $80 \%$ of the fibre weight. A cavity is situated in the middle of the elementary fibres (lumen). These walls ( $\left.S_{1}, S_{2}, S_{3}, P\right)$ consist of micro fibrils $[13,14]$. Figure 2 shows the composition of micro fibrils.

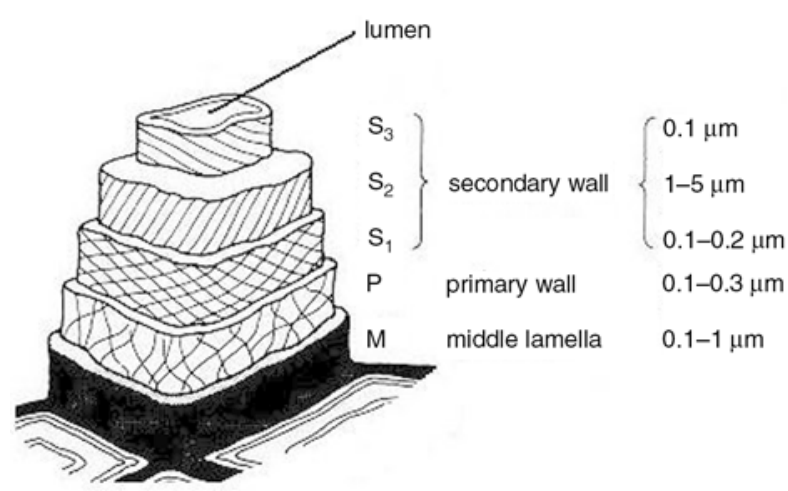

Figure 1. Composition of the elementary fibres of wood [13]

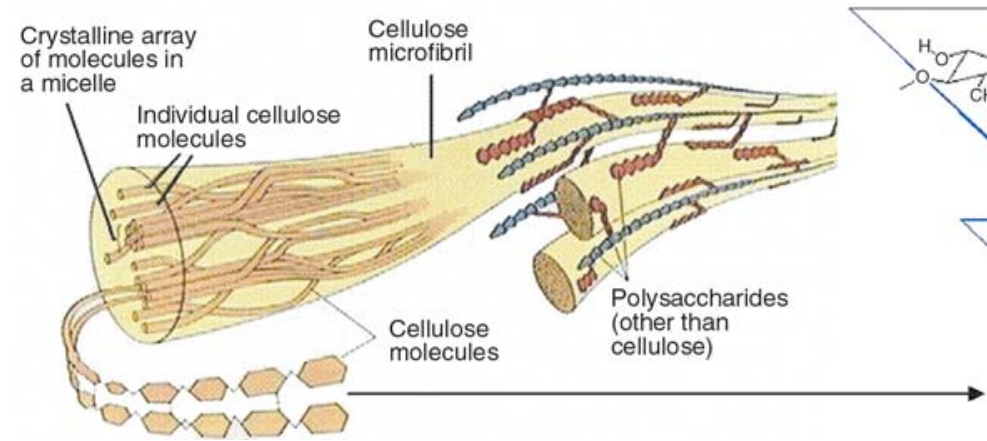

Figure 2. Composition of a cellulose fibril (left) and structure of the cellulose level (right) [15]
The micro fibril itself consists of approx. 60 cellulose chains. The interconnected cellulose chains belong to the crystalline areas (micelle) and single cellulose chains to the amorphous areas.

Water absorption primarily takes place in the amorphous areas of cellulose and in hemicelluloses. During this process, mainly the thicker layer of the secondary wall expands. The mechanical properties of the fibres do not only depend on the orientation of the cellulose fibrils, which exhibit a varying gradient towards the major axis of the fibre depending on the fibre type, but also on other parameters like, degree of polymerization, degree of crystallinity, pore structure, and chemical composition of the fibres [7, 13, 16, 17].

Cellulose and hemicelluloses contain several hydroxyl groups in their structure that can form hydrogen bonds with water molecules. The result is a reversible moisture expansion of the fibre that can change the mechanical characteristics. The watercellulose interdependencies are subject to the water content of the fibres and the temperature [16].

In general, three kinds of water retention can be distinguished: free water, bound water, and capillary water. Free water is located in the lumen and described as stored water above fibre saturation. Bound water is absorbed in the cellular walls until fibre saturation. The third type of water retention takes place in the pores of the fibre wall above fibre saturation by means of capillary action [18]

Especially wood has a very large inner surface because of its microscopic capillary porosity. Consequently, it can absorb moisture from the air or other surrounding media (adsorption) or emit it (desorption). The depiction of the interdependence between relative wood moisture and relative air moisture at a constant temperature (and air pressure) level characterizes a sorption (Figure 3). Dur-

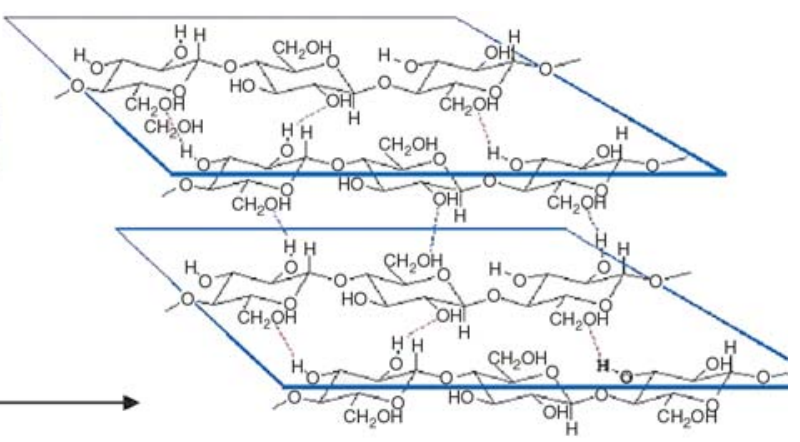




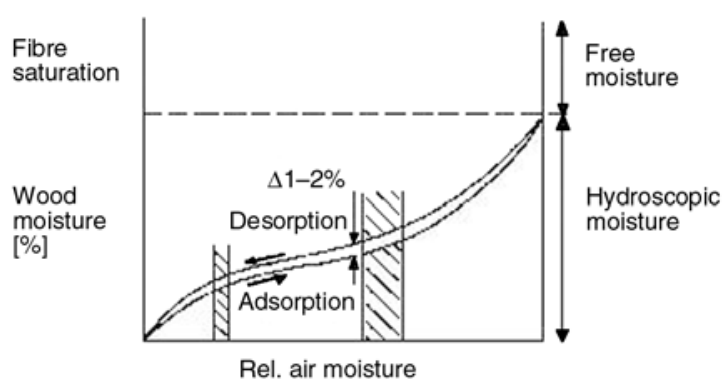

Figure 3. Typical sorption isotherm for wood [19]

ing desorption, the equilibrium moisture content is $1-2 \%$ higher than during absorption. In the case of a directional sorption, this behaviour is shown by a hysteresis curve.

Sorption takes place in the hygroscopic area and is only valid until fibre saturation. According to (DIN EN 844-4), fibre saturation is the state of a wood sample when the cellular walls are saturated with water, and there should be no water in the cellular cavities. Wood moisture depending on the kind of wood is individually assigned to a specific temperature and air moisture [19].

Thus, moisture absorption is equally divided into three phases: chemical absorption, physical absorption, and capillary condensation (Table 1).

During chemical absorption, which takes place at $0-20 \%$ of rel. humidity $(R H)$, the monomolecular water layer is bound to the cellulose. In this process, the water dipoles orientate themselves towards the negative poles of the exposed $\mathrm{OH}$ groups of cellulose. As long as no crystalline areas are displaced, hardly any external volume extension follows the molecular sorption. The phase of adsorption extends from approx. 20-60\% of $R H$. The attachment of water molecules happens by means of electrostatic and Van der Waals' forces. Yet, the polymolecular water layer developed this way is distributed unevenly. The water molecules depend less on the boundary layer with increasing layer thickness. They begin to show fluid characteristics (surface tension, flowability). Above approx. $60 \%$ of $R H$, less vapour saturation pressure leads to capillary condensation. This condensation still takes place in the cellular wall structure. The water is adsorbed in the intermicellular and interfibrillar cavities. Only when the fibrils cannot extend anymore because of the relatively strong bonds in the crystalline areas, fibre saturation is completed and the end of the hygroscopic area is reached $[10,11$, 19,20]. The sorption phases overlap each other and occur locally distributed. The sorption behaviour is influenced by temperature.

\section{Experimental part}

\subsection{Materials}

\subsubsection{Wood fibres (particle)}

The soft wood fibres BK 40-90 (spruce), provided by J. Rettenmaier \& Söhne GmbH + Co.KG Rosenberg, Germany, were used as filling material (see Tables 2 and 3).

\subsubsection{Matrix}

The polypropylene Homopolymer SABIC ${ }^{\circledR}$ PP 575P, provided by the company Sabic Euro Petrochemicals B.V., Sittard, Netherlands, was used as matrix polymer.

Table 2. Characteristics of used wood fibres

\begin{tabular}{|l|l|}
\hline Name & Lignocel $^{\circledR}($ BK 40-90) \\
\hline Type & soft wood (spruce) \\
\hline Structure & cubic \\
\hline Particle area & $300-500 \mu \mathrm{m}$ \\
\hline Colour & yellow \\
\hline pH-value & $5.5 \pm 1$ \\
\hline Density & $1.5 \mathrm{~g} / \mathrm{cm}^{3}$ \\
\hline
\end{tabular}

Table 3. Chemical composition of employed wood fibres in weight [\%] [21]

\begin{tabular}{|l|c|c|}
\hline \multirow{2}{*}{$\begin{array}{c}\text { Main components } \\
\text { of the fibres }\end{array}$} & \multicolumn{2}{|c|}{ Soft wood fibres } \\
\cline { 2 - 3 } & Literature [10, 19] & Experimental \\
\hline Cellulose & $40-45$ & 43 \\
\hline Hemicellulose & $25-30$ & 24 \\
\hline Lignin & $26-34$ & 30 \\
\hline Extracts & $0-5$ & 3 \\
\hline
\end{tabular}

${ }^{1}$ the references do not refer to the product Lignocel Chemical

Table 1. Kinds of water bonds in wood $[10,11]$

\begin{tabular}{|c|c|c|c|}
\hline Relative air moisture & Wood moisture & Moisturization-drying phase & Water bonds \\
\hline $0-20 \%$ & $0-6 \%$ & chemical absorption & bound water \\
\hline $20-60 \%$ & $6-15 \%$ & physical absorption & bound water \\
\hline above $60 \%$ & below $30 \%$ & capillary condensation & bound water \\
\hline $100 \%$ & above $30 \%$ & capillary condensation & free water \\
\hline
\end{tabular}


Table 4. Characteristic data of the employed matrix materials

\begin{tabular}{|l|c|c|}
\hline \multicolumn{1}{|c|}{ Characteristics } & Polypropylene & Coupling agent \\
\hline Trade name & SABIC ${ }^{\circledR} \mathrm{PP} 575 \mathrm{P}$ & Licomont AR 504 \\
\hline Chemical nomination & Isotactic PP & Maleic anhydride grafted PP \\
\hline Density & $0.905 \mathrm{~g} / \mathrm{cm}^{3}$ & $0.89-0.93 \mathrm{~g} / \mathrm{cm}^{3}$ \\
\hline Vicat-temperature & $152^{\circ} \mathrm{C}$ & $154-158^{\circ} \mathrm{C}$ \\
\hline Viscosity & - & $\sim 800 \mathrm{mPa} \cdot \mathrm{s}$ \\
\hline MFR & $10.5 \mathrm{~g} / 10 \mathrm{~min}\left(230^{\circ} \mathrm{C} / 2.16 \mathrm{~kg}\right)$ & $>1000 \mathrm{~g} / 10 \mathrm{~min}\left(190^{\circ} \mathrm{C} / 2.16 \mathrm{~kg}\right)$ \\
\hline Acid value & - & $37-45 \mathrm{mg} \mathrm{KOH} / \mathrm{g}$ \\
\hline
\end{tabular}

\subsubsection{Coupling agent}

Maleic anhydride grafted polypropylene (MAH$\mathrm{PP}$ ), provided by Clariant Produkte GmbH Gersthofen, Germany, was used as coupling agent. The information given by the manufacturers about their matrix polymers and coupling agents is listed in Table 4.

\subsection{Manufacturing of the specimens}

Wood fibre was mixed with PP using a high speed mixer (Henschel Mixer, type HM40 KM120) with and without coupling agent (MAH). The soft woof fibre (SW) was dried at $80^{\circ} \mathrm{C}$ in an air circulating oven for $24 \mathrm{~h}$ (until the moisture content became $<1 \%$ ) before mixing. The fiber content is $50 \%$. The specimens of wood fibre composites were prepared by injection moulding using a Klöckner Ferromatik FM 85 . At 160 to $180^{\circ} \mathrm{C}$ and with the mould temperature kept at 80 to $100^{\circ} \mathrm{C}$.

\subsection{Conditioning of the fibres}

With percental moisture content, the relation between the mass of moisture in the wood and the mass of dry wood is denoted. For this reason, the dried wood fibres $(3 \mathrm{~g})$ were stored at a relative humidity of 65 and $95 \%$ as well as an ambient temperature of $20 \pm 3^{\circ} \mathrm{C}$. The moisture absorption in equilibrium was determined with a precision of $0.0001 \mathrm{~g}$. The wood fibre samples were weighed after certain periods of time $(24,48,96 \mathrm{~h}$ etc.) until they reached a constant weight (saturation point). In doing so, a double determination was carried out and the resulting value was represented as average value.

\subsection{Conditioning of the samples}

The composites were conditioned under different circumstances. The immediate influence of water (by static water conditioning) as well as the results of cyclic moisturization-dehydration on physical and especially mechanical data were determined. The data of all conditioned samples were compared with the values of the samples conditioned in standard climate. In this context, it is important to know in how far the manipulations are irreversible or can be reversible by subsequent dehydration.

\subsubsection{Conditioning in standard climate}

The term 'samples conditioned in standard climate' refers to those samples which were exclusively stored at standard climate (DIN 50014) in the testing room for 48 hours and tested without further conditioning.

\subsubsection{Static and cyclic water absorption}

Static water absorption was determined according to DIN EN ISO 62. Cyclic water absorption took place in accordance with the same standard.

During cyclic storage in water, the materials were soaked in water for $24 \mathrm{~h}$ and were dried at the same temperatures for $24 \mathrm{~h}$; this represents a cycle.

\subsubsection{Static and cyclic climate conditioning}

The ageing of the samples took place in appropriate conditioning cabinets. Static climate conditioning was carried out according to DIN EN 60068-2-78. The WPC samples were conditioned over 6 weeks at $40^{\circ} \mathrm{C}$ and with a relative humidity of $95 \%$.

Figure 4 shows the implemented climatic cycle which took $24 \mathrm{~h}$. 


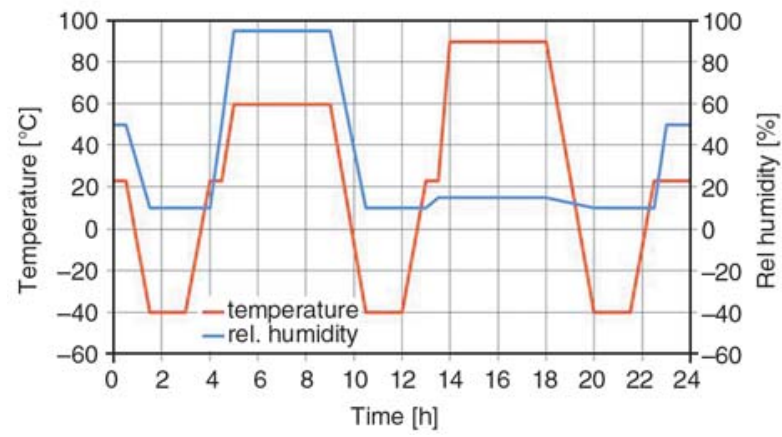

Figure 4. Adjustment parameters of the cyclic climate test

The following conditions were integrated: dry/cold, warm/humid, hot/dry, and a standard condition $\left(23^{\circ} \mathrm{C} / 50 \% R H\right)$.

\subsection{Bending test}

The determination of bending properties was carried out according to DIN EN ISO 178 using injection-moulded standard specimens in a universal testing machine type Zwick1446. Depending on the ambient climate, 5 to 10 specimens were used.

\section{Results and discussion}

\subsection{Moisture absorption of the wood fibres}

The moisture absorption was investigated at a relative moisture level of 65 and $95 \%$ and at an ambient temperature of $20 \pm 3^{\circ} \mathrm{C}$. Figure 5 shows the differing moisture absorptions of soft wood fibres.

The investigations carried out show that the speed of moisture absorption depends on the degree of moisture. Accelerated moisture absorption occurred

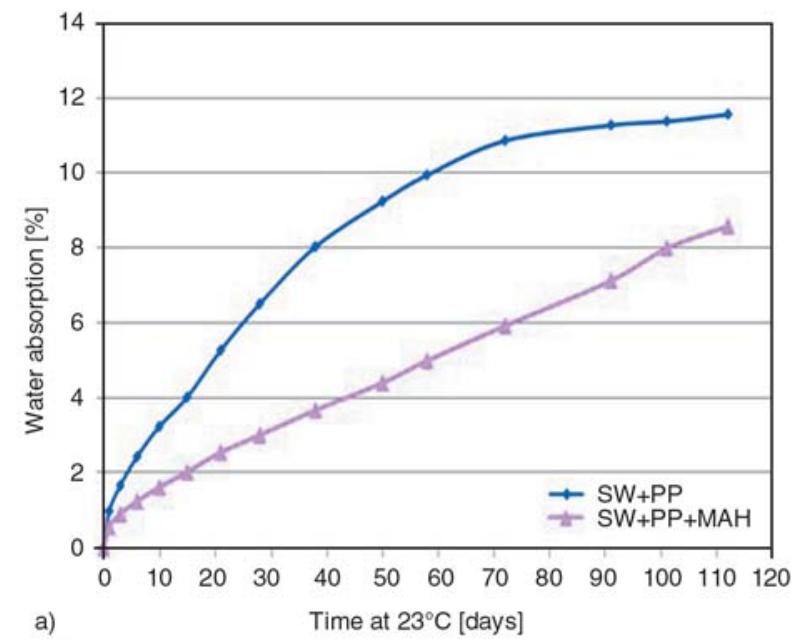

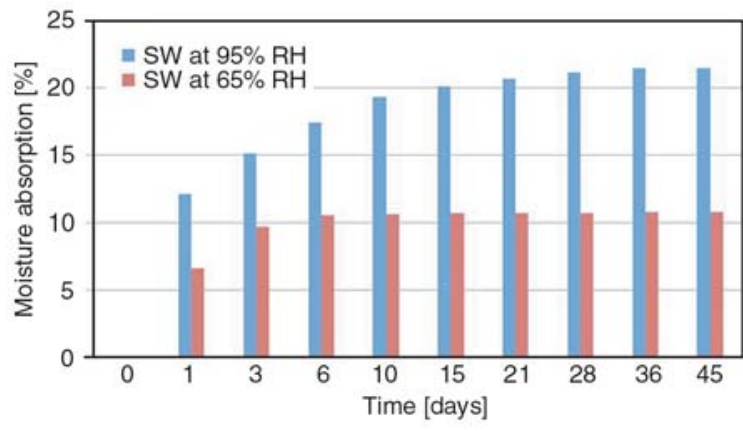

Figure 5. Influence of relative air moisture on moisture absorption of soft wood fibres (SW)

during the first three days at a moisture level of $65 \%$ and up to ten days at a level of $95 \%$. The equilibrium moisture of the soft wood fibres was reached after two weeks at $65 \%$ of $R H$ and after about three weeks at $95 \%$ of $R H$.

\subsection{Static water absorption of the composites}

The influence of coupling agent application and conditioning temperature on static water absorption of wood composites is depicted in Figure 6.

It was determined that water absorption takes place in a higher amount and faster at $50^{\circ} \mathrm{C}$-conditioning. Within three months during static water storage at ambient temperature, approximately the same percentage amount of water was absorbed as within one month at $50^{\circ} \mathrm{C}$. In both cases, the modified samples show lower water absorption in comparison to the untreated ones. The difference between untreated and modified WPCs after 112 days of water conditioning is about $26 \%$ at $23^{\circ} \mathrm{C}$ and about $11 \%$ at $50^{\circ} \mathrm{C}$.

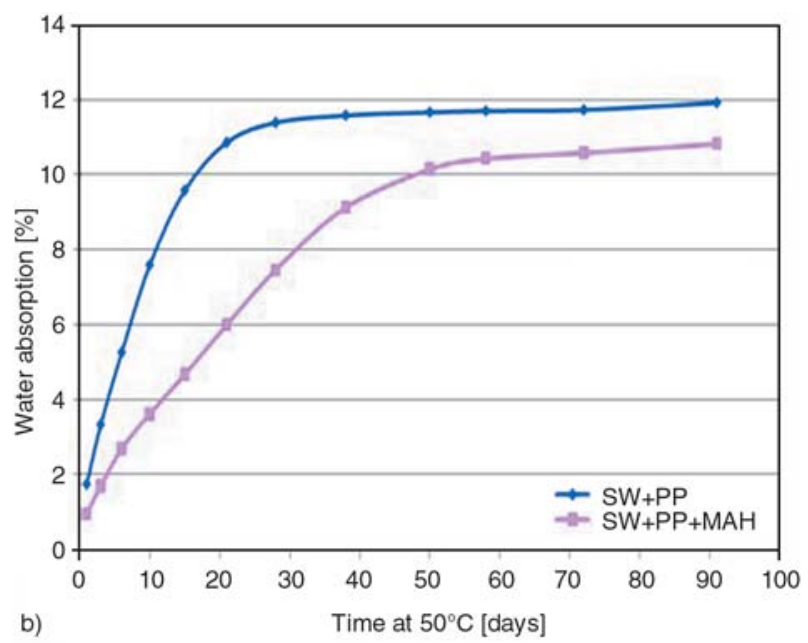

Figure 6. Influence of fibre modification and conditioning temperature on static water absorption of WPC 


\subsection{Cyclic water absorption of the composites} In order to compare the experimental results of static water conditioning, cyclic water absorption was carried out at 23 and $50^{\circ} \mathrm{C}$. The influence of the temperature on cyclic water absorption behaviour is depicted in Figure 7.

Despite the augmentation in conditioning temperature which leads to an increase in water absorption, the water absorption and-desorption of the samples have mainly proven to be reversible.

At both conditioning temperatures, the modified samples exhibit lower water absorption in comparison to the untreated composites.

As for static water absorption, the conditioning temperature is an important factor here. With increasing temperature, the water absorption of the composites increases by approximately $50 \%$ after 50 days in comparison to the WPC's conditioned at $23^{\circ} \mathrm{C}$.

Besides, periodic water conditioning shows that after 50 days, the composites conditioned in cycles exhibit a water absorption which is $40 \%\left(50^{\circ} \mathrm{C}\right)$, and $52 \%\left(23^{\circ} \mathrm{C}\right)$ respectively, lower in comparison to the samples stored in water under static conditions. With regard to the materials treated with
MAH-PP, the difference is approximately $42 \%$ $\left(23^{\circ} \mathrm{C}\right)$, and $56 \%\left(50^{\circ} \mathrm{C}\right)$ respectively.

As the storing period includes moisturization and drying, the results of water absorption behaviour after 50 days of cyclic storage were compared with that of static water conditioning after 25 days. The difference in water content between the material stored under static and that stored under cyclic conditions is up to $25 \%$ at $23^{\circ} \mathrm{C}$ and approximately $35 \%$ at $50^{\circ} \mathrm{C}$.

\subsection{Bending experiments after static water absorption}

The influence of static water storage on the bending properties of WPC is shown in Figure 8.

Static water conditioning clearly influences the bending stability. At both conditioning temperatures, a considerable decrease of the characteristic values was observed. The composites treated with MAH-PP possess a bending stability which is up to $35 \%$ higher in comparison to the unmodified materials; but a clear reduction (approx. 30\%) of the characteristic values of the treated wood-PP was observed due to this conditioning.
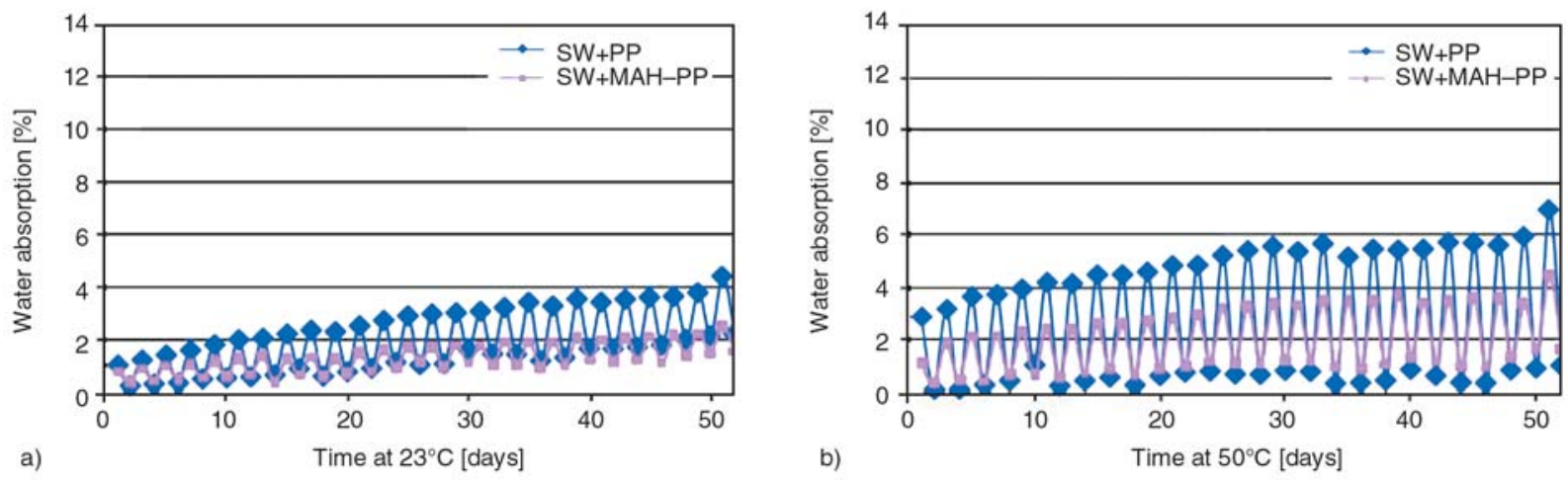

Figure 7. Influence of fibre modification and conditioning temperature on cyclic water absorption of WPC
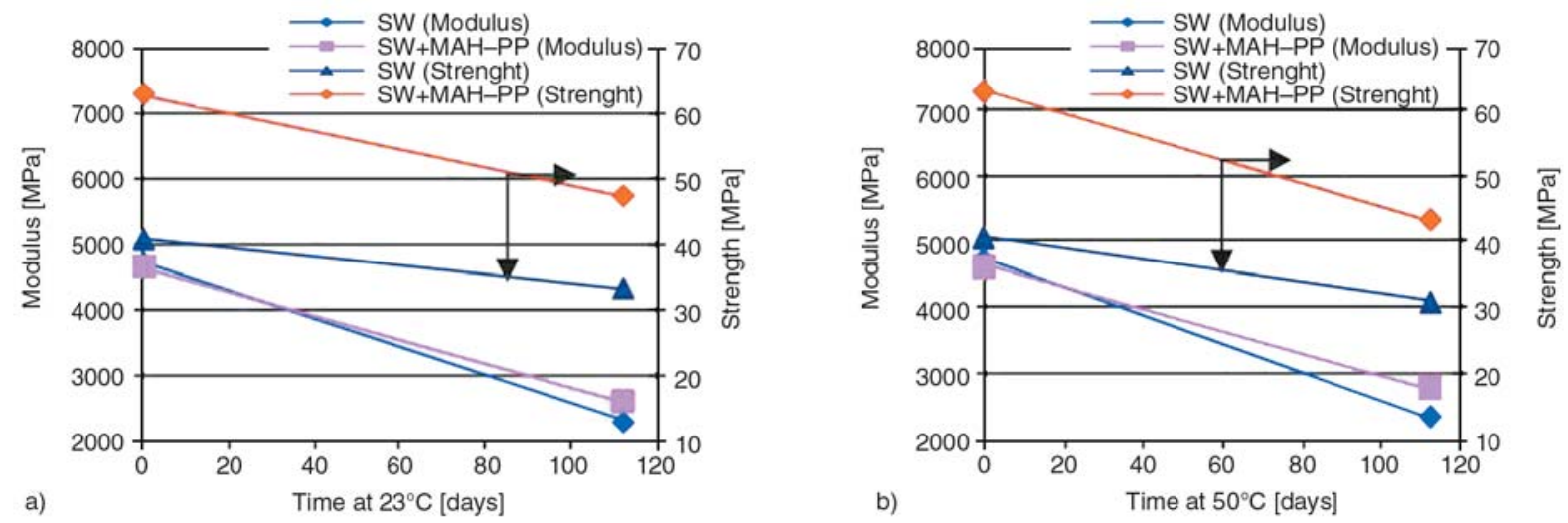

Figure 8. Influence of static water storage on the bending properties of WPC (arrows refer to the axes) 
By absorbing moisture, wood plastic composites normally undergo a kind of softening, that is, with increasing moisture content, the stiffness of the materials decreases. Apart from this, a higher temperature can be detected which undoubtedly plays a role as well.

\subsection{Bending experiments after cyclic water absorption}

After 10, 20 and 30 cycles of cyclic water storage, bending experiments were carried out (Figure 9).

These figures show that cyclic water storage at $23^{\circ} \mathrm{C}$ does not cause a remarkable change of the bending stabilities of the set treated with a coupling
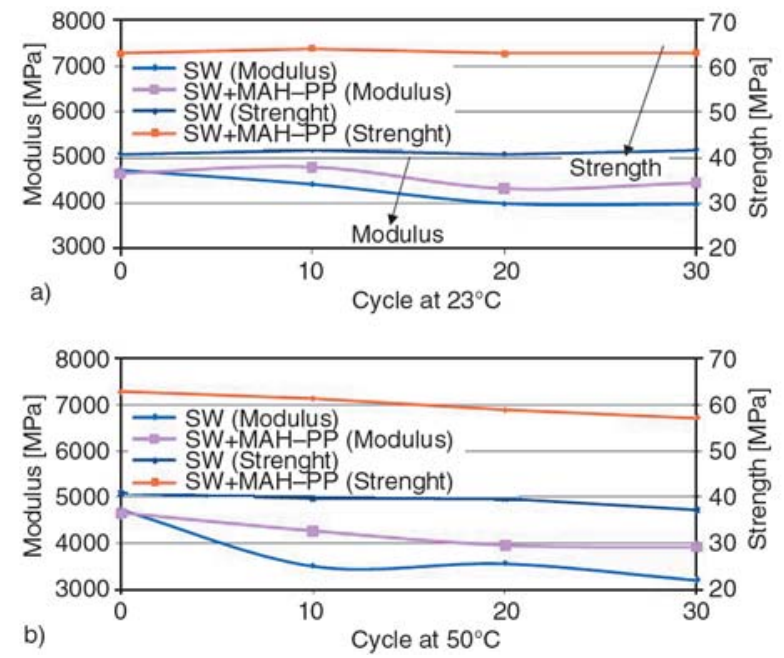

Figure 9. Influence of cyclic water storage on the bending properties of WPC

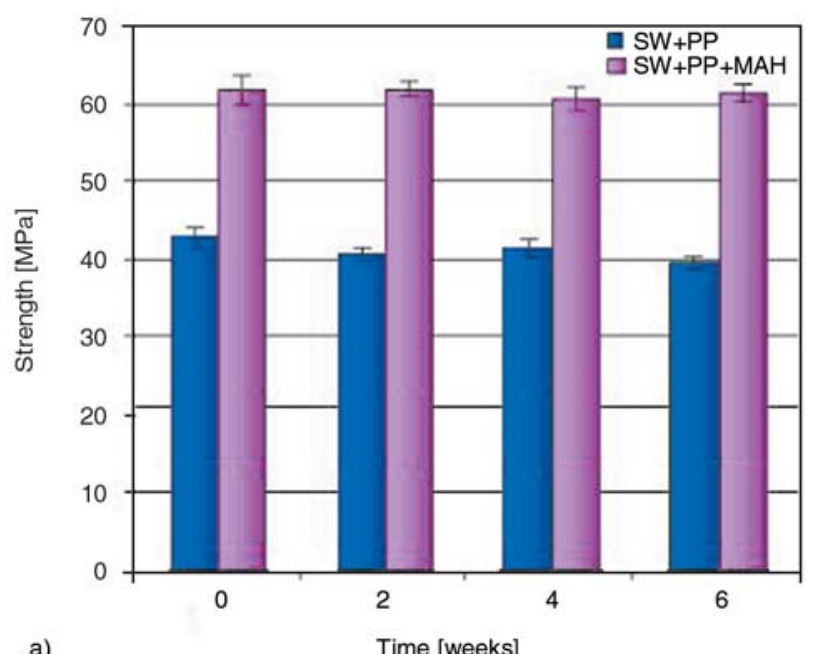

agent and the untreated one. At $50^{\circ} \mathrm{C}$, a small decrease in stiffness (approx. 10\%) can be observed. The specimens treated with MAH-PP altogether show a bending stability that is approx. $40 \%$ higher than that of the untreated materials. Due to this, the first irreversible effects of cyclic conditioning can be observed with regard to the bending stabilities.

At both conditioning temperatures, a reduction of the $E$-modulus could be detected. The highest decrease in stiffness (approx. 32\%) can be observed in the untreated materials.

\subsection{Bending experiments after static climate conditioning}

The influence of static climate conditioning on the bending properties of WPC was investigated as well (see Figure 10).

It was determined that the stability values of all materials show no significant differences. In this context, the materials which were treated with a coupling agent exhibit a bending stability up to $36 \%$ higher than the untreated composites.

In comparison to the unconditioned samples, the characteristic values of the moduli of modified and unmodified WPC's decreased, and especially those of the non-modified composites by approx. $24 \%$ after six weeks of storing. Additionally, the WPCs treated with a coupling agent show slightly higher stiffness values in comparison to the untreated materials here.

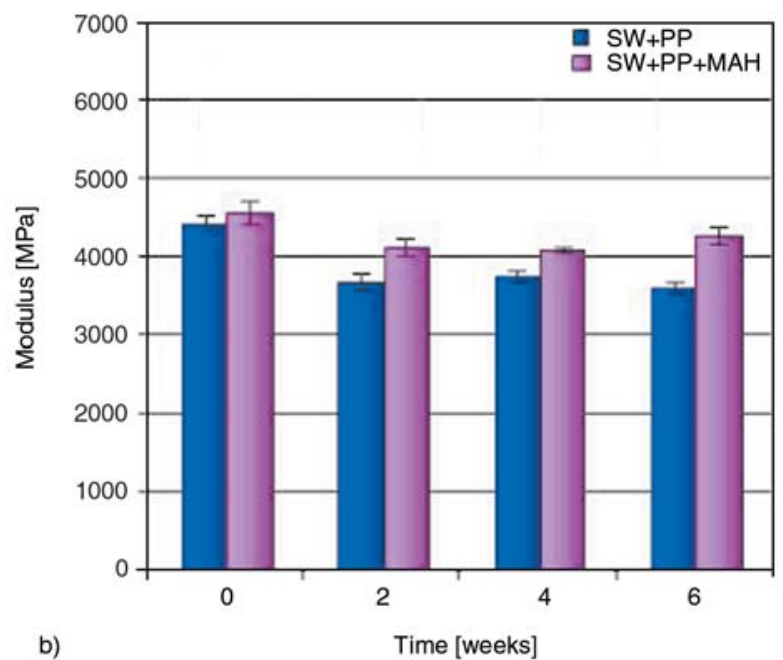

Figure 10. Influence of static climate conditioning $\left(40^{\circ} \mathrm{C}, 95 \%\right.$ of $\left.R H\right)$ on the bending properties of WPC 


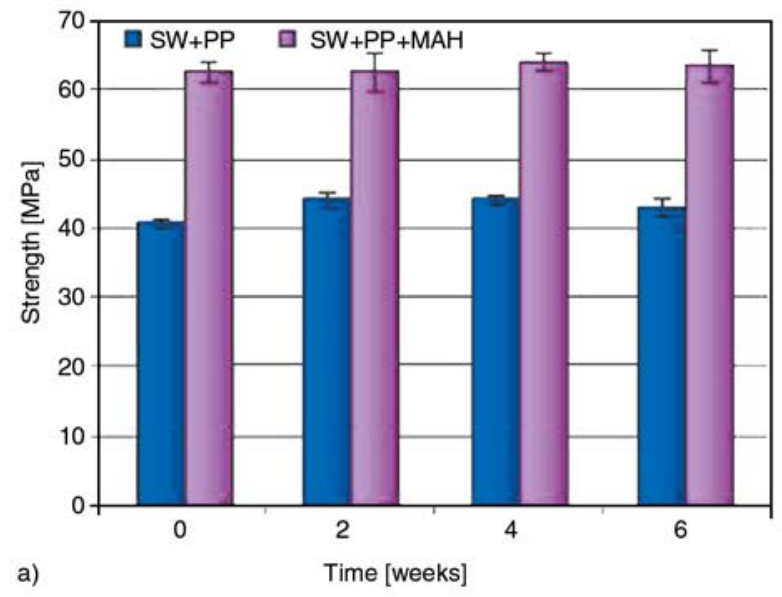

Figure 11. Influence of cyclic climate conditioning

\subsection{Bending experiments after cyclic climate conditioning}

The following Figure 11 shows the bending behaviour of the WPC-materials after storage in Cyclic Climate.

While there are only slight changes within the test series, the samples treated with a coupling agent show no change in bending stability after six weeks of storing in comparison to the unconditioned sample. The modified WPC-samples show stiffness values that are up to $32 \%$ higher than those of the unmodified sets.

The stiffness values are only marginally influenced by cyclic conditioning.

The investigations carried out prove that the stability- and stiffness values of WPC remain unchanged after six weeks of climatic exposition in comparison to the untreated.

\section{Conclusions}

Static and cyclic water absorption:

- The higher temperature $\left(50^{\circ} \mathrm{C}\right)$ causes water absorption to become higher and three times faster.

- At both temperatures, a significant decrease $(20-30 \%)$ of the mechanical data was determined, while the materials treated with a coupling agent have characteristic values that are approx. 35\% higher.

- The cyclic sorption graph increases asymptotically and causes significantly lower water absorption in comparison to the statically stored samples.

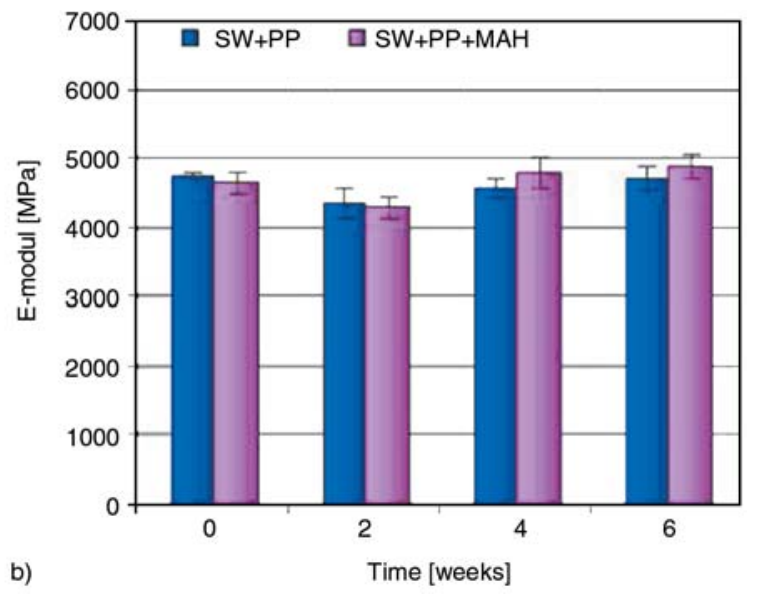

- The mechanical characteristics show no decrease in stability values after two months of cyclic water storage at $23^{\circ} \mathrm{C}$ and only a slow decrease at $50^{\circ} \mathrm{C}$. However, at both conditioning temperatures, a reduction of the modulus was detected.

Static and cyclic climate conditioning:

- While the stability values were hardly influenced, slight changes in the characteristic values can be observed with regard to the modulus.

- After six weeks of cyclic climate conditioning, approx. the same mechanical values of all materials were measured as in the original sample.

It was shown that the a higher temperature can accelerate the absorption rate and volume of WPCs. Coupling agents causes an improvement of moisture resistance and mechanical properties in WPC. Besides, it could be proved that after cyclic influences on moisture and temperature and subsequent drying, the mechanical values of the composites are at the level of the original data.

\section{References}

[1] Bledzki A. K., Sperber V. E., Faruk O.: Natural and wood fibre reinforcement in polymers. Rapra, Shrewsbury (2002).

[2] Dale Ellis W., O’Dell J. L.: Wood-polymer composites made with acrylic monomers, isocyanate, and maleic anhydride. Journal of Applied Polymer Science, 73, 2493-2505 (1999).

DOI: $10.1002 /($ SICI $) 1097-4628(19990919) 73: 12<$ 2493::AID-APP18>3.0.CO;2-C

[3] Bledzki A. K., Gassan J.: Composites reinforced with cellulose based fibres. Progress in polymer Science, 24, 221-274 (1999). DOI: $\underline{10.1016 / \mathrm{S} 0079-6700(98) 00018-5}$ 
[4] Jäger A.: Market growth WPC. Biowerkstoff-Report, 7, 18-19 (2010).

[5] Rowell R. M.: Handbook of wood chemistry and wood composites. Taylor and Francis, New York, (2005).

[6] Nechwatal A., Reußmann T., Böhm S., Richter E.: The dependence between the process technologies and the effect of MAH-PP-adhesives in natural fibre reinforced thermoplastic composites. Engineering Materials, 7, 68-73 (2005).

DOI: $\underline{10.1002 / \text { adem.200400138 }}$

[7] Rowell R. M., Lange S. E., Jacobson R. E.: Weathering performance of plant fiber/thermoplastic composites. Molecular Crystals and Liquid Crystals, 353, 85-94 (2000). DOI: $10.1080 / 10587250008025650$

[8] Ichazo M. N., Albano C., González J., Perera R., Candal M. V.: Polypropylene/wood flour composites: Treatments and properties. Composites Structures, 54, 207-214 (2001).

DOI: $\underline{\text { 10.1016/S0263-8223(01)00089-7 }}$

[9] Cantero G., Arbelaiz A., Mugika F., Valea A., Mondragon I.: Mechanical behavior of wood/polypropylene composites: Effects of fibre treatments and ageing processes. Journal of Reinforced Plastics and Composites, 22, 37-50 (2003).

DOI: $10.1177 / 0731684403022001495$

[10] Ruch J., Fritz H. G.: Compounding and characterisation of long fibre reinforced composites based on flax and polypropylene. in 'ANTEC 2002, 60th Annual Technical Conference, San Francisco, USA' Vol 2, 2180-2184 (2002).

[11] Gassan J.: Naturfaserverstärkte Kunststoffe- Korrelation zwischen Struktur und Eigenschaften der Fasern und deren Compositen. PhD thesis, Universität Kassel (1997).
[12] Bledzki A. K., Sperber V. E., Specht K., Letman M., Viksne A.: Effect of defined waxes and coupling agents on moisture behavior of injection molded wood fiber reinforced PP composites. in ' $8^{\text {th }}$ International Conference on Woodfiber-Plastic Composites (and other Natural Fibers), Madison, USA' 229-238 (2005).

[13] Fengel D., Wegener G.: Wood-chemistry, ultrastructure, reactions. European Journal of Wood and Wood Products, 42, 314 (1984).

DOI: $\underline{10.1007 / \mathrm{BF} 02608943}$

[14] Wagenführ R.: Anatomie des Holzes. DRW-Verlag, Leinfelden-Echterdingen (1999).

[15] Letman M.: Holzgefüllte Kunststoffe- eine kreative Werkstoffinnovation für technische Anwendungen. $\mathrm{PhD}$ thesis, Universität Kassel (2007)

[16] Klemm D., Philip B., Heinze T.: Comprehensive cellulose chemistry. Volume 1: Fundamentals and analytical methods. Wiley, Weinheim (1998).

[17] Schneider Ch.: Chemische und morphologische Veränderungen von Zellstoffen während der Bleiche und deren Auswirkung auf die technologischen Eigenschaften. PhD thesis, TU-Darmstadt (2000).

[18] Thienel K. Ch.: Bauchemie und Werkstoffe des Bauwesens: Holz, Skript zur Vorlesung. Universität München, München (2006).

[19] Niemz P.: Physik des Holzes und der Holzwerkstoffe. DRW Verlag, Leinfelden-Echterdingen (1993).

[20] Kollmann F.: Technologie des Holzes und der Holzwerkstoffe, Band 1. Springer, Berlin (1951).

[21] Bledzki A. K., Letman M., Viksne A., Rence L.: A comparison of compounding processes and wood type for wood fibre-PP composites. Composites Part A: Applied Science and Manufacturing, 36, 789-797 (2005). DOI: $10.1016 /$ j.compositesa.2004.10.029 